\title{
Genome composition and divergence between Russian boreal species in the genus Elymus (Poaceae), as assessed by nuclear gene GBSS1 sequencing
}

\author{
Agafonov A.V. ${ }^{*}$, Shabanova (Kobozeva) E.V. ${ }^{1}$, Asbaganov S.V. ${ }^{1}$, \\ Morozov I.V. ${ }^{2,3}$, Bondar A.A. ${ }^{2}$ \\ ${ }^{1}$ Central Siberian Botanical Garden, SB RAS, Novosibirsk, Russia \\ ${ }^{2}$ Genomics Core Facility, Institute of Chemical Biology and Fundamental Medicine, SB RAS, Novosibirsk, \\ Russia \\ ${ }^{3}$ Novosibirsk State University, Novosibirsk, Russia \\ *e-mail:agalex@mail.ru
}

Serial studies have been conducted previously by Dr. Mason-Gamer to confirm that the molecular phylogenetic analysis of sequences in the low copy gene granule-bound starch synthase 1 ( GBSS1) significantly complements the cytogenetic data for the genomic constitution and evolutionary relationships both among North American and Asian species of the genus Elymus. We sequenced and compared GBSS1 gene in 14 endemic Elymus species from Siberia and the Russian Far East in order to determine their genomic constitution and to assess the levels of divergence and phylogenetic differentiation. The species are: E. charkeviczii, E. jacutensis, E. kamczadalorum, E. komarovii, E. kronokensis, E. lenensis, E. macrourus, E. margaritae, E. subfibrosus, E. sajanensis, E. transbaicalensis, E. peschkovae, E. uralensis, E. viridiglumis. PCR-amplified gene fragments spanned from exon 9 to exon 14 were cloned, and six clones per each species accession have been sequenced. All of them included St and $\mathrm{H}$ subgenomic variations of the gene. Most profound differences between St and H subgenomic fragments were located in the intron 13. This intron in the subgenome $\mathrm{H}$ contains a large deletion of $21 \mathrm{bp}$ in all Elymus genotypes, likely obtained from a common ancestor of the $\mathrm{H}$ and $\mathrm{P}$ genomes. In place of this deletion all St and Y subgenomes have a relatively conservative sequence that is almost identical in nucleotide composition to the closely related genus Pseudoroegneria, whose ancestor is the donor of the modern St subgenome of all Elymus species. The phylogenetic cluster analysis revealed microevolutionary events and considerably added our previous biosystematic results in the group of boreal species from Siberia and the Russian Far East. New data obtained are needed for the construction of a phylogenetically oriented taxonomic system of the genus within Russia. 